\title{
BMJ Open Understanding parents' experiences of disease course and influencing factors: a 3-year follow-up qualitative study among parents of children with functional abdominal pain
}

\author{
Mette Brekke (D), Anne Brodwall
}

To cite: Brekke M, Brodwall A. Understanding parents' experiences of disease course and influencing factors: a 3-year follow-up qualitative study among parents of children with functional abdominal pain. BMJ Open 2020;10:e037288. doi:10.1136/ bmjopen-2020-037288

- Prepublication history for this paper is available online. To view these files, please visit the journal online (http://dx.doi. org/10.1136/bmjopen-2020 037288).

Received 03 February 2020 Revised 28 July 2020 Accepted 30 July 2020

Check for updates

(C) Author(s) (or their employer(s)) 2020. Re-use permitted under CC BY-NC. No commercial re-use. See rights and permissions. Published by BMJ.

General Practice Research Unit, Department of Health and Society, University of 0slo, Oslo, Norway

Correspondence to

Dr Anne Brodwall;

abrodwa@online.no

\section{ABSTRACT}

Objective Functional abdominal pain is a common symptom in children and adolescents. Three years ago, we investigated the experiences among parents whose children had chronic abdominal pain but no somatic diagnosis. The aim of the present follow-up study was to explore those families' current situations.

Design Interviews with open questions about the families' current pain situations were carried out by the first author. Interviews were audio-recorded and transcribed, and subsequently analysed using descriptive content analysis. Setting Urban and rural areas in two municipalities in Southern Norway.

Participants Parents of children with abdominal pain who had been referred to a local hospital by their general practitioner and had been discharged without a somatic diagnosis. Fifteen parents of 14 children aged 8-17 years who had also been interviewed in 2016 .

Results Nine of the children had recovered from their abdominal pain. During the pain period, the parents reported frustration with not having a diagnosis nor a specific treatment for their child's abdominal pain. The siblings in some families received less attention and were afraid that something serious might happen to their sister or brother. The parents wished that their child's school cared more about the child when they had weeks of absence. All parents maintained that their child's pain was physical, although they thought that psychological aspects might have influenced the symptoms. The parents stated that they, as well as their children, needed guidance from professionals to understand the complex pain situation.

\section{INTRODUCTION}

Functional gastrointestinal disorder (FGID) is a common diagnosis among children and adolescents with gastrointestinal tract symptoms who present to primary care physicians or gastroenterologists. The Rome criteria have become the standard for defining FGID, which is characterised by chronic or recurrent digestive symptoms without an underlying somatic disease or biochemical abnormality. ${ }^{1}$ The diagnosis is based exclusively on
Strengths and limitations of this study

- The main strength of the present study is that the complete cohort of parents who had been interviewed 3 years ago agreed to be interviewed again.

- Another strength is that the same researcher carried out all interviews on both occasions.

- The use of semistructured interviews enabled detailed information about the parents' experiences over the 3 years.

- The sample size is small, and with one exception only one of the parents in each family was interviewed.

- Only parents well integrated into the society were approached.

symptoms reported by the children and the parents, and the condition has no biological markers. ${ }^{1}$

In 1958, British paediatrician John Apley ${ }^{2}$ published his pioneering research into children with abdominal pain, which was then called recurrent abdominal pain; this has now been replaced by FGID. Apley ${ }^{2}$ found that $11 \%$ of British schoolchildren had FGID and stated: 'It is a fallacy that a physical symptom always has a physical cause and needs a physical treatment'. He was the first to establish criteria to define FGID as a distinct syndrome. ${ }^{3}$

Complaints of chronic abdominal pain occur in $10 \%-19 \%$ of children, with prevalence highest in children aged 4-6years and in early adolescence. ${ }^{4}$ The prevalence rates of chronic abdominal pain among school-age children in the USA and Europe range from $0.3 \%$ to $19 \% .^{5}$ In almost $90 \%$ of these children, no explanatory organic cause can be identified. ${ }^{6}$ There are no significant differences in FGID related to sex, race or ethnic groups, except in functional constipation, which is significantly more prevalent in 
male compared with female patients. ${ }^{7}$ There is overlap between parental and child FGID symptoms. Children with FGID report a lower quality of life compared with healthy children. ${ }^{7}$

The child's or adolescent's and their family's life quality is negatively impacted by chronic abdominal pain. Families of children with chronic pain generally have poorer family functioning than do healthy populations. Painrelated disability is more consistently linked to family function than to pain intensity. ${ }^{8}$ Research has demonstrated that parents of children with chronic pain also experience negative mental and social outcomes. ${ }^{9}$ Understanding the cause of the pain seems to be important for recovery, and parents tend to be open to psychosocial interventions for their child's pain, such as stress reduction or relaxation exercises, and want to discuss both physical and psychological aetiological factors and treatment opinions. ${ }^{10}$ Difficulties within the family may increase the child's pain, which may in turn negatively affect the parents and family life. ${ }^{11}$ Young people with chronic pain and their parents often experience uncertainty about the diagnosis, which may be linked to their acceptance of it and response to treatment. ${ }^{12}$ Parents frequently state that they feel helpless when faced with their child's suffering. These fears and worries may explain why parents reinforce illness behaviours by showing empathy for an apparently sick child. ${ }^{13}$

In a study published in 2018, we carried out interviews with parents of 14 children with chronic abdominal pain who had been discharged from the hospital without a somatic explanation. ${ }^{14}$ The study concluded that functional pain in children and adolescents is challenging for the patient and the family and that they often need medical support for a long period. Three years after the first interviews, we wanted to learn how these children and their families were progressing, by again interviewing the parents. By following these families over some years, we could gain valuable information about the children's symptoms and treatment. To our knowledge, a follow-up qualitative study such as this has previously not been conducted in this patient group. Thus, our aim was to investigate the course of the child's abdominal pain, what may have helped, how the family's situation had been influenced and whether they had any unmet needs.

\section{METHODS}

\section{Participants}

In 2016, the first author carried out an interview study with 15 parents of 14 children with chronic abdominal pain. ${ }^{14}$ She deliberately aimed at a broad age span (from 5 to 15 years), and the children included were between 6 and 13.5 years old. All had been referred to a hospital in a medium-sized Norwegian city that serves around 500 000 inhabitants. The child's general practitioner (GP) had not found an explanation for the abdominal pain, and subsequent hospital investigations had not revealed any specific pathology. The only exclusion criterion was an inability to communicate in the Norwegian language. Recruitment was carried out consecutively face to face among eligible families by a nurse at the hospital. After 14 interviews, data saturation had been reached and recruitment stopped. Details about the original recruitment process are given in our previous article. ${ }^{14}$ The parents also agreed to be invited to an interview again in 3 years. In 2019, the first author contacted the parents by telephone and arranged an interview meeting. All parents accepted the invitation. As in 2016, a qualitative design with individual interviews was used.

\section{Interviews}

The parents were interviewed by the first author, a female GP who is also a child and adolescent psychiatrist and works at the hospital's child psychiatric department. The parents knew that the interviewer was a physician; in the interview setting, however, she presented herself as a researcher with a special interest in FGID, but with no therapeutic responsibility. The interviewer was empathetic, although neutral, and encouraged the parents to speak freely. The interviews took place in locations that suited the parents, usually at the interviewer's office or at the parents' workplaces, with no one else present. Four interviews were conducted by phone because the parents had moved or were on vacation. Each interview lasted 30-60 min. A semistructural interview guide was used by the author, but not provided to the participants (figure 1). The first author audio-recorded and transcribed the interviews. The transcripts were not returned to the participants for comments.

\section{Data analysis}

Qualitative content analysis was conducted based on the work by Graneheim and Lundman. ${ }^{15}$ Both authors read the transcripts individually and worked together on their analysis to achieve a common understanding and to reinforce the level of trust and credibility. ${ }^{15}$ The transcripts were read several times. The text was sorted into meaning units, shortened and coded. These codes were then sorted into categories and subcategories. From the categories,

1. Concerning the stomach pain - how is your child doing at present?

2. Concerning the stomach pain - how has the situation been during the last 3 years? For the child? For the family?

3. How has the child's pain affected the family? Parents? Siblings?

4. How has improvement or worsening of the pain affected the family?

5. Has the child been followed up by a GP or by the hospital during the last 3 years?

6. Has the child seen any other health personnel?

7. What do you think has contributed to the child's improvement/worsening?

8. Is there anything more I should have asked?

9. How did you experience this interview?

Figure 1 Interview guide. GP, general practitioner. 
three main themes emerged. No software tool was used for the analyses. The authors discussed the codes, categories and themes until agreement was reached. The themes were derived from the data, not identified in advance.

\section{Patient and public involvement}

No patients were involved.

\section{RESULTS}

\section{Participant and child information}

In total, 15 parents of 14 children were interviewed: 9 mothers, 4 fathers and 1 couple. Ten of the parents were ethnic Norwegians. Four were of foreign origin but had lived in Norway for several years and spoke Norwegian fluently. All but two parents currently cohabitated with their child's other parent. In 2016, the interviewed children, seven boys and seven girls, were 6-13.5 years old; during the present study they were $9-17$ years old. Thirteen children had siblings; nine had one sibling, two had two siblings, and two had three siblings.

\section{Current status of the children's abdominal pain}

In the 3 years since the original interview, nine of the children had recovered from abdominal pain, and in three of them the pain persevered. In two of the children, the situation was unclear (table 1). 'Recovered' was defined as no subjective complaints and return to school and other activities. The boys and the girls who had recovered ranged in age from 10.5 to 17 years and from 8.8 to 15 years, respectively. The three children who still had pain were 9,10 and 11.5 years old.

We identified three main themes:

- Family burden and frustration, and how school issues implied a major dilemma.

- The consequences of improvement.

- Desire for a diagnosis and for advice.

Theme 1: family burden and frustration, and how school issues implied a major dilemma

Nearly all the parents reported that the child's pain had affected their family. Half of the children (three boys and four girls) had been absent from school, and six of them had missed several weeks. The parents had to stay home from work or arrange for a caregiver on these days. "We tried to avoid being absent from work. The grandparents stayed with her. In the end I had to get a sick leave because she was at home for more than 2 months" (Interview 14).

Some parents had to stay with their child all day and night. The strain affected the family dynamics and disrupted the normal daily life in the family, like having

\begin{tabular}{|c|c|c|c|}
\hline & Total (n) & Girls & Boys \\
\hline Recovered & 9 & 4 & 5 \\
\hline Still with symptoms & 3 & 1 & 2 \\
\hline Unsure situation & 2 & 2 & 0 \\
\hline
\end{tabular}

common meals and normal sleeping patterns. "She was sick at night too. We became like zombies. We slept some hours each in her room. We ate in bed together with her" (Interview 14). Some parents feared that their worries could negatively affect the child. Not knowing the diagnosis and fear of serious illness influenced their everyday lives. "My frustration spreads to him and so he reads me and I read him" (Interview 2).

\section{Effect on siblings}

Siblings' reaction varied widely from not noticing the symptoms at all to being significantly affected. "His big brother thinks he is a drama queen, that he exaggerates the symptoms" (Interview 8). In several of the families, younger siblings expressed difficulties with having an older brother or sister who experienced abdominal pain. The parents had less time to take care of the siblings. "His little brother gets a little overlooked because his sister takes such a great pass. I myself as mother feel pity for him" (Interview 4).

Some of the siblings' teachers had noticed that the child was affected by the situation at home. "He talked about his dark thoughts at home. That was tough for his little brother to hear. He got sad and his teacher noticed that. The atmosphere in the house was the worst" (Interview 10).

\section{The school situation: a major dilemma}

More than half of the parents were concerned about their child's school situation and that the abdominal pain was influenced by problems there. Some reported that when the school situation got better, the child's abdominal pain also recovered. "She has started secondary school, started in a new class and is much better physically as well as psychologically" (Interview 11). The parents argued that children and adolescents were under a great deal of stress and that school contributed to this. Some worried that the school did not take the situation seriously. "There is little communication with the school. We had hoped that the school had something to contribute. They knew about the problems, but did not take us seriously" (Interview 11$)$.

Some of the parents elaborated on their dilemma by sending the child to school on days with abdominal pain. They explained that they knew school attendance was compulsory and important for social relationships and for the treatment, yet it was problematic for the parents. They expressed fear of being poor parents by forcing their child to go. "They told us at the hospital that she should try to go to school again. But I told them it will not be possible for me to send her to school when she has pain" (Interview 14).

\section{Theme 2: the consequences of improvement}

Nine of the 14 children ( 5 boys and 4 girls) had recovered by the time of the follow-up interview. For six of these, the parents did not know the reason for the child's recovery. Three of the children had been helped by treatments 
for constipation and reflux symptoms. One parent explained: "The pain disappeared, the child just grew out of it" (Interview 7). One parent wondered what the child meant by "stomach pain" because she did not appear to be in pain. "She cannot define it more clearly herself. Is this real pain or is it more a feeling of air in the guts? Could the pain be an excuse or cover other problems for the child?" (Interview 13).

Recovery from abdominal pain influenced the families and made the situation better for all family members. "Her mood is much better now, so that makes it easier for her siblings and I can lower my shoulders" (Interview 1).

The children did not want their parents to worry; in turn, the parents wondered whether their children answered their questions accurately or hid their symptoms. They also wondered how this long pain period would affect the child's development. "This stomach pain has lasted several years. What will this do to him as a person? How will he be as an adult?" (Interview 1).

\section{Theme 3: desire for a diagnosis and for advice}

Some of the parents emphasised that getting a diagnosis had made the child better. "He was terrified, had stomach pain all the time and did not understand why. It helped him a lot to get the diagnosis and know that we could do something about it" (Interview 10). A diagnosis was also important to the parents. The discussion about when to stop pursuing further examinations to find a diagnosis was difficult. To stop investigations before the child had a diagnosis seemed not acceptable. "We are so desperate about the pain situation. I am fully aware of the academic foundation that it is expensive and takes resources, but as a parent it would have calmed me down" (Interview 1).

The follow-up from the hospital was reported as frustrating by some of the parents: "I want more co-operation between patient/parents and hospital, it would have made the treatment more effective. It is important to look at the whole story, all factors together" (Interview 10). The parents reported having been told that "it is up to you to try" and they missed guidance over time by a doctor or nurse.

All the parents thought, as they did in 2016, that the abdominal pain was a physical condition. However, some also thought that there could be psychological factors (such as school problems, problems with friends and so on) that affected the pain. Four of the children had talked to a child and adolescent psychologist, and another one parent had asked for that type of appointment, but their request was not fulfilled. Two children sought guidance from a family member with psychological expertise. Two parents reported that their child did not need to talk to a psychologist.

\section{DISCUSSION}

Fifteen parents of 14 children with FGID who had been discharged from hospital without an identified somatic cause were interviewed in 2016 and again for the present study in 2019. During the intervening years, nine children had recovered from their abdominal pain. For six of these, no reason for their recovery had been identified. The parents reported frustration with not having a somatic diagnosis for their child, they missed having closer contact with a doctor, and cooperation with school was poor. All parents maintained that their child's pain was physical, although they thought that psychological aspects might have influenced the symptoms. The parents thought it was impossible and inhumane to force the child to school on days with pain.

Previous studies have stated the importance of school also in pain periods. ${ }^{16}{ }^{17}$ According to a study by Lowth ${ }^{16}$, parents should be advised to reduce concerned responses to their child's pain, focusing on distraction instead. Walker $e \mathrm{al}^{17}$ state that the abdominal pain may be related to separation anxiety, and that parents' role and mindset need to be changed from protecting the child from possible harm to being a coach to encourage and support the child to engage in normal activities. The goal of treatment thus will be return to normal activities, rather than removing pain. The parents in the current study wanted a closer cooperation with school and believed that it was a prerequisite to successful treatment. However, they emphasised that this was complicated and frustrating. This makes psychoeducation and support to these families over time an important part of the treatment. ${ }^{16}$ Some parents worried about the impact of long-term pain on their child's development. This topic has been discussed in other studies. ${ }^{18}$ The child's possibility to a successful stepping forward into adult life also must be an aspect of the treatment. ${ }^{18}$

In families with more than one child, the parents' tasks seem complex, as they need to care for both the child with abdominal pain and the siblings. Parents with chronically ill children have been described to live in a never-ending battle, which is challenging for the whole family. ${ }^{19}$ It is known that siblings of children with FGID have significantly higher mean levels of emotional and/ or behavioural symptoms compared with siblings of comparable, healthy children. ${ }^{20}$ The siblings' involvement in our study ranged from very serious concerns to not caring.

Michael Balint ${ }^{21}$ wrote about the concept of 'the child as the presenting symptom'. When a child was repeatedly taken to see a GP, it was often found that the parents also needed therapy, usually of an emotional, psychological nature. These families often seem vulnerable to being misunderstood and misinterpreted. Consequently, their doctors should be both agile and clear with treatment recommendations. ${ }^{21}$ Simultaneously, a study from 2018 showed that the parents were highly strained due to the demands of their role as caregivers to a child with functional abdominal pain. ${ }^{22}$ The parents' behaviour can be seen as operant factors that serve to either increase or decrease adaptive child behaviour. ${ }^{23}$ This concern was also raised by the participants in our study, as some parents raised the question of whether their worries about their 
child's symptoms might impact the child and maintain their pain.

It is important both to exclude organic causes and to identify eventual positive indications of emotional problems. ${ }^{24}$ Crushell et $a l^{25}$ found that only 1 in 14 parents of children with ongoing pain believed that there was a psychological cause for their child's pain. All our respondents believed their child's abdominal pain had physiological causes, although some thought psychological aspects could influence the symptoms. These expressions could explain why so few of the children had spoken to a psychologist. Nevertheless, it is important to include psychological therapy such as cognitive-behavioural therapy in the treatment plan. ${ }^{16}$ Psychological interventions for managing paediatric chronic pain have involved the parents in treatment using this approach, that is, teaching the parents techniques to increase adaptive child behaviours such as rewarding the child's school attendance. ${ }^{24}$ Parents' problem-solving methods overall, not just regarding health problems, usually affect their children. The adults in a family are, in most cases, the child's role models. Palermo et $\mathrm{l}^{26}$ reported that parents' emotions, behaviours and health play a role in children's pain experiences.

The expression "grew out of the pain" was used by 6 of the 14 parents in our study. A study from 2020 also stated that most children do not have persistent symptoms throughout childhood. ${ }^{27}$ Our participants seemed to be satisfied with this solution and had no further need for more detailed knowledge.

The parents in our study reported in both interviews (ie, in 2016 and again in 2019) that it was frustrating not having a diagnosis. To deal with the abdominal pain became difficult when the diagnosis was uncertain. Having had somebody to talk to about the pain or being provided with an explanation from the doctor would have made the situation better. Several studies reveal a clear desire by parents for information about the causes of their child's pain, treatment options available and for effective strategies to enhance their child's ability to cope with pain. ${ }^{162028}$

\section{Strengths and limitations}

The first author and interviewer is a GP and a child and adolescent psychiatrist. When conducting the interviews, she presented herself as a researcher, to emphasise that she had no therapeutic responsibilities in this setting and that the parents could speak freely. We expect that this improved both the interview quality and interpretation. The interview participants were mainly ethnic Norwegians; other ethnic groups might have responded differently.

\section{CONCLUSION}

A child having functional pain is challenging for the child as well as the parents and siblings. The goal of the treatment is helping the child and the family to return to normal function, like attending school and other activities. This underlines the importance of psychoeducation about the symptoms and pain treatment strategies. Cognitive-behavioural therapy or other psychological interventions may help the families, and follow-up over time by a trusted physician is essential.

Acknowledgements We are grateful to all parents sharing their experiences with us.

Contributors Both authors planned the study. MB applied for ethics approval. AB carried out the interviews and transcribed the text, and both authors participated in the analyses. $A B$ drafted the article, and $M B$ revised it critically.

Funding This study was supported by a grant from The Norwegian Committee on Research in General Practice.

Competing interests None declared.

Patient consent for publication Not required.

Ethics approval The Regional Committees for Medical and Health Research Ethics approved the study (reference no 2019/646).

Provenance and peer review Not commissioned; externally peer reviewed.

Data availability statement No data are available. The data are deidentified interviews transcribed in full text.

Open access This is an open access article distributed in accordance with the Creative Commons Attribution Non Commercial (CC BY-NC 4.0) license, which permits others to distribute, remix, adapt, build upon this work non-commercially, and license their derivative works on different terms, provided the original work is properly cited, appropriate credit is given, any changes made indicated, and the use is non-commercial. See: http://creativecommons.org/licenses/by-nc/4.0/.

ORCID iD

Mette Brekke http://orcid.org/0000-0003-3454-2329

\section{REFERENCES}

1 Rasquin A, Di Lorenzo C, Forbes D, et al. Childhood functional gastrointestinal disorders: child/adolescent. Gastroenterology 2006;130:1527-37.

2 Apley J, Naish N. Recurrent abdominal pains: a field survey of 1,000 school children. Arch Dis Child 1958;33:165-70.

3 Shumann JV, Deacy AD, Friesen CA. Recurrent abdominal pain. In: McGrath PJ, Stevens BJ, Walker S, eds. Oxford textbook of paediatric pain. Oxford UK: Oxford University Press, 2013: 289-97.

4 Fishman MB, Aronsen MD, Chacko MR. Chronic abdominal pain in children and adolescents: approach to the evaluation, 2019. Available: https://www.uptodate.com/contents/chronic-abdominalpain-in-children-and-adolescents-approach-to-the-evaluation

5 Chitkara DK, Rawat DJ, Talley NJ. The epidemiology of childhood recurrent abdominal pain in Western countries: a systematic review. Am J Gastroenterol 2005;100:1868-75.

6 Spee LAA, Lisman-Van Leeuwen Y, Benninga MA, et al. Prevalence, characteristics, and management of childhood functional abdominal pain in general practice. Scand J Prim Health Care 2013;31:197-202.

7 Lewis ML, Palsson OS, Whitehead WE, et al. Prevalence of Functional Gastrointestinal Disorders in Children and Adolescents. $J$ Pediatr 2016;177:39-43.

8 Lewandowski AS, Palermo TM, Stinson J, et al. Systematic review of family functioning in families of children and adolescents with chronic pain. J Pain 2010;11:1027-38.

9 Le A, Dick BR, Spiers J, et al. Parents' experiences with pediatric chronic pain. Can J Pain 2019;3:20-32.

10 van Tilburg MAL, Chitkara DK, Palsson OS, et al. Parental worries and beliefs about abdominal pain. J Pediatr Gastroenterol Nutr 2009;48:311-7.

11 Palermo TM. Impact of recurrent and chronic pain on child and family daily functioning: a critical review of the literature. J Dev Behav Pediatr 2000;21:58-69.

12 Neville A, Jordan A, Beveridge JK, et al. Diagnostic uncertainty in youth with chronic pain and their parents. J Pain 2019;20:1080-90.

13 van Tilburg MAL, Venepalli N, Ulshen M, et al. Parents' worries about recurrent abdominal pain in children. Gastroenterol Nurs 2006;29:50-5. 
14 Brodwall A, Glavin K, Lagerløv P. Parents' experience when their child has chronic abdominal pain: a qualitative study in Norway. BMJ Open 2018;8:e021066.

15 Graneheim UH, Lundman B. Qualitative content analysis in nursing research: concepts, procedures and measures to achieve trustworthiness. Nurse Educ Today 2004;24:105-12.

16 Lowth M. Recurrent abdominal pain in children. Patient 2017;6:1-9.

17 Walker LS, Beck J, Anderson J. Functional abdominal separation anxiety: helping the child return to school. Pediatr Ann 2009;38:267-71.

18 Reid K, Lander J, Scott S, Shannon S, et al. What do the parents of children who have chronic pain expect from their first visit to a pediatric chronic pain clinic? Pain Res Manag 2010;15:158-62.

19 Sjøgård M. Føreldrars kamp før sitt barn. (Parents' fights for their child). Ábo Akademi University, 2019.

20 Guite JW, Lobato DJ, Shalon L, et al. Pain, disability, and symptoms among siblings of children with functional abdominal pain. $J$ Dev Behav Pediatr 2007;28:2-8.

21 Balint M. The doctor, his patient and the illness. London, UK: Churchill Livingstone, 2000.
22 Calvano C, Warschburger P. Quality of life among parents seeking treatment for their child's functional abdominal pain. Qual Life Res 2018;27:2557-70.

23 Palermo TM, Eccleston C. Parents of children and adolescents with chronic pain. Pain 2009;146:15-17.

24 Lask B, Fosson A. Childhood illness: the psychosomatic approach. Chichester, UK: John Wiley \& Sons, 1989.

25 Crushell E, Rowland M, Doherty M, et al. Importance of parental conceptual model of illness in severe recurrent abdominal pain. Pediatrics 2003;112:1368-72.

26 Palermo TM, Valrie CR, Karlson CW. Family and parent influences on pediatric chronic pain: a developmental perspective. Am Psychol 2014;69:142-52.

27 Sjölund J, Uusijärvi A, Tornkvist NT, et al. Prevalence and progression of recurrent abdominal pain, from early childhood to adolescence. Clin Gastroenterol Hepatol 2020;25:30592-9.

28 Chacko MR, Chiou E. Chronic abdominal pain in children and adolescents: management in primary care, 2019. Available: https:// www.uptodate.com/contents/functional-abdominal-pain-in-childrenand-adolescents-management-in-primary-care 